Zagazig Veterinary Journal, @Faculty of Veterinary Medicine, Zagazig University, 44511, Egypt.

Volume 47, Number 1, p. 32-44, March 2019

DOI: $10.21608 / z v j z .2019 .6030 .1014$

\title{
The Role of Infectious Bronchitis Virus in Respiratory and Renal Problems in Broiler
} Chickens

\author{
Ali M.Mahmoud ${ }^{1}$, Abeer M. Shahin ${ }^{2}$ and Amal A.M. Eid ${ }^{2 *}$ \\ ${ }^{1}$ Directorate of Veterinary Medicine, Mansoura - General Organization for Veterinary \\ Services, Egypt \\ ${ }^{2}$ Avian and Rabbit Medicine Department , Faculty of Veterinary Medicine, Zagazig \\ University, 44511, Egypt
}

Article History: Received: 11/11/2018 Received in revised form: 21/12/2018 Accepted: 16/1/2019

\begin{abstract}
Broiler chickens in Egypt represent the main source of animal protein. Unfortunately, they usually are hit by many disease problems. Respiratory and renal affections are investigated in forty four broiler chicken flocks aged (19-54) days and suffering from respiratory and renal distress during 2014-2015 in three large Governorates; Sharkia, Dakahlia and Gharbia Variable mortality rates $(0.5-30 \%)$ were recorded. On necropsy, tracheitis, bronchitis and congestion of lungs were recorded in all examined flocks. Caseated plugs at tracheal bifurcation 28/44, fibrinous pericarditis, perihepatitis and air sacculitis 19/44 were also observed. Nepherosisnephritis 22/44, and General congestion with hemorrhage on proventriculus 9/44 and cecal tonsil 4/44 were seen among affected birds. Chicken embryo inoculation for IBV isolation revealed reduction in embryo size was recorded in $20 \%$, death within $72 \mathrm{~h}$ in $54.5 \%$ while $11 \%$ of flocks required successive blind passage to show reduction in embryo size up to $2 \mathrm{~cm}$ compared to $5 \mathrm{~cm}$ in negative control. Thirty three out of forty four harvested allantoic fluids were positive with Heamagglutination test (75\%). The reverse transcriptase polymerase chain reaction (RT-PCR) was carried out on both original tissues and allantoic fluids using specific primers for S1 gene. Nine positive infectious bronchitis viruses (IBVs) (20\%) were detected in original samples compared with only $2(4.5 \%)$ in allantoic fluids of the same samples. It could be concluded that the IB virus infection did not exceed $20 \%$ of the causative agents in disease condition in question and usually in mixed infection. In turn the use of variant vaccines did not solve the problem but exacerbated the emergence of new IB viruses. There were clear evidence that HA virus did the main role in such disease problems. The direct RT-PCR could be reliable tool for appropriate IBV diagnosis to estimate the real situation in chicken diseases.
\end{abstract}

Key word: IBV, Respiratory, Renal, RT-PCR, HA viruses.

\section{Introduction}

Poultry industry is considered an important pillor in Egyptian economy. Broiler chickens as a major source of animal proteins are threatened by many pathogens that substracte the profit of this sector. Respiratory and renal troubles are commonly recorded among flocks [1-3]. Infectious bronchitis is one of important disease affecting respiratory and /or urogenital systems in broilers all over the world [4] In addition, morbidity as high as (100\%) and mortality $(\leq 30 \%)$ occurs in young chickens in nephropathogenic strains. The disease is exaggerated by secondary bacterial infections leading to increased mortality rate in broiler flocks [4].Infectious bronchitis virus (IBV) is one of genus corona viruses, family coronaviridae, order nidovirals, more than 20 serotypes within IB viruses have been identified worldwide $[5,6]$.

Variant IB viral strains emergence has complicated the problem. Outbreaks with these variant strains usually differ serologically from the vaccine strains. Despite using both classic and variant types of IB vaccines, economic losses still occurred continuously by IB virus

*Corresponding author e-mail (amalaeidvet@gmail.com), Avian and Rabbit Medicine Department,

Faculty of Veterinary Medicine, Zagazig University, 44511, Egypt. 
causing clinical disease and production problems in vaccinated flocks [7-11]

The IB virus has two spike glycopolypeptides S1 and S2. Neutralizing and serotype specific antibodies have mainly bounded for the S1 glycoprotien [12]. Consequently, the identification of IB viruses mostly focused on S1 gene analysis [13].

\section{Materials and Methods}

\section{Clinical and postmortem examination}

Broiler chicken farms $(n=44)$ suffering from respiratory and renal distress were investigated during 2014-2015. The study included three Governorates Sharkia, Dakhalia and Gharbiathe. Gharbia. A comprehensive descriptive data were obtained (Table.1).Clinical and postmortem examination the birds were $(n=5-10)$ examined clinically and postmortem lesions were recorded.

Table 1: Data of the Chicken Broiler Flocks examined in Sharkia, Dakhlia and Gharbia Governorates during 2014-2015

\begin{tabular}{|c|c|c|c|c|c|c|c|}
\hline $\begin{array}{c}\text { Flock } \\
\text { number }\end{array}$ & $\begin{array}{c}\text { Date of } \\
\text { sampling }\end{array}$ & Locality & Breed & $\begin{array}{c}\text { Age } \\
\text { (days) }\end{array}$ & $\begin{array}{c}\text { Total } \\
\text { number }\end{array}$ & Mortality* & Previous vaccination \\
\hline 1 & $15-12-2014$ & Gharbia & Cubb & 30 & 1400 & $10 \%$ & $\begin{array}{c}\text { IB primer } 1 \mathrm{~d}- \\
\text { ND+H9 inactivated } 5 \mathrm{~d}- \\
\text { IBMA5+Clone } 18 \mathrm{~d}\end{array}$ \\
\hline 2 & $15-12-2014$ & Gharbia & Sasso & 45 & 6000 & $3 \%$ & $\begin{array}{l}\text { IB primer } 1 \mathrm{~d}- \\
\text { ND+H9 inactivated } 5 \mathrm{~d}- \\
\text { IBMA5+Clone } 18 \mathrm{~d}\end{array}$ \\
\hline 3 & $15-12-2014$ & Gharbia & Sasso & 29 & 8000 & $0.5 \%$ & Not vaccinated \\
\hline 4 & $19-12-2014$ & Gharbia & Sasso & 38 & 6000 & $2 \%$ & $\begin{array}{l}\text { IB primer 1d- } \\
\text { ND+H9 inactivated 9d- } \\
\text { IBMA5+Clone } 17 d\end{array}$ \\
\hline 5 & $20-12-2014$ & Gharbia & Cubb & 30 & 2000 & $2 \%$ & $\begin{array}{c}\text { IB primer 1d- } \\
\text { LaSota+ H9 7d- } \\
\text { ND inactivated 15d- } \\
\text { IBMA5+Clone 19d }\end{array}$ \\
\hline 6 & $22-12-2014$ & Gharbia & Cubb & 33 & 2400 & $12 \%$ & $\begin{array}{c}\text { IB primer } 1 \mathrm{~d}- \\
\mathrm{ND}+\mathrm{H} 9 \text { inactivated } 8 \mathrm{~d}- \\
\text { Clone } 17 \mathrm{~d}\end{array}$ \\
\hline 7 & $1-1-2015$ & Gharbia & Cubb & 35 & 10000 & $4 \%$ & $\begin{array}{c}\text { IB primer } 1 \mathrm{~d}- \\
\text { ND+H9 inactivated 5d- } \\
\text { IBMA5+Clone 18d- } \\
\text { LaSota 30d }\end{array}$ \\
\hline 8 & $6-1-2015$ & Gharbia & Sasso & 26 & 5000 & $5 \%$ & $\begin{array}{c}\text { IB primer } 1 \mathrm{~d}- \\
\text { ND+H9 inactivated } 5 \mathrm{~d}- \\
\text { IBMA5+Clone } 18 \mathrm{~d}\end{array}$ \\
\hline 9 & $6-1-2015$ & Gharbia & Cubb & 23 & 2000 & $9 \%$ & $\begin{array}{c}\text { IB primer } 1 \mathrm{~d}- \\
\text { ND+H9 inactivated } 8 \mathrm{~d}- \\
\text { IB } 4 / 9115 \mathrm{~d} \\
\text { Clone } 30 \mathrm{~d}\end{array}$ \\
\hline 10 & $12-1-2015$ & Gharbia & Cubb & 25 & 700 & $8.5 \%$ & Not Vaccinated \\
\hline 11 & $10-2-2015$ & Gharbia & Cubb & 30 & 2200 & $2.5 \%$ & IB + Hitchener B11d \\
\hline 12 & $10-12-2014$ & Dakahlia & Cubb & 27 & 1900 & $6 \%$ & $\begin{array}{l}\text { IB primer 1d- } \\
\text { IB } 4 / 9114 d\end{array}$ \\
\hline 13 & $12-1-2015$ & Dakahlia & Sasso & 54 & 7700 & $2.5 \%$ & $\begin{array}{c}\text { IB primer 1d- } \\
\text { ND+ H9 inactivated 5d } \\
\text { IBMA5+Clone 18d- } \\
\text { LaSota } 42 \mathrm{~d}\end{array}$ \\
\hline 14 & $6-1-2015$ & Sharkia & Cubb & 30 & 1000 & $30 \%$ & Not Vaccinated \\
\hline
\end{tabular}




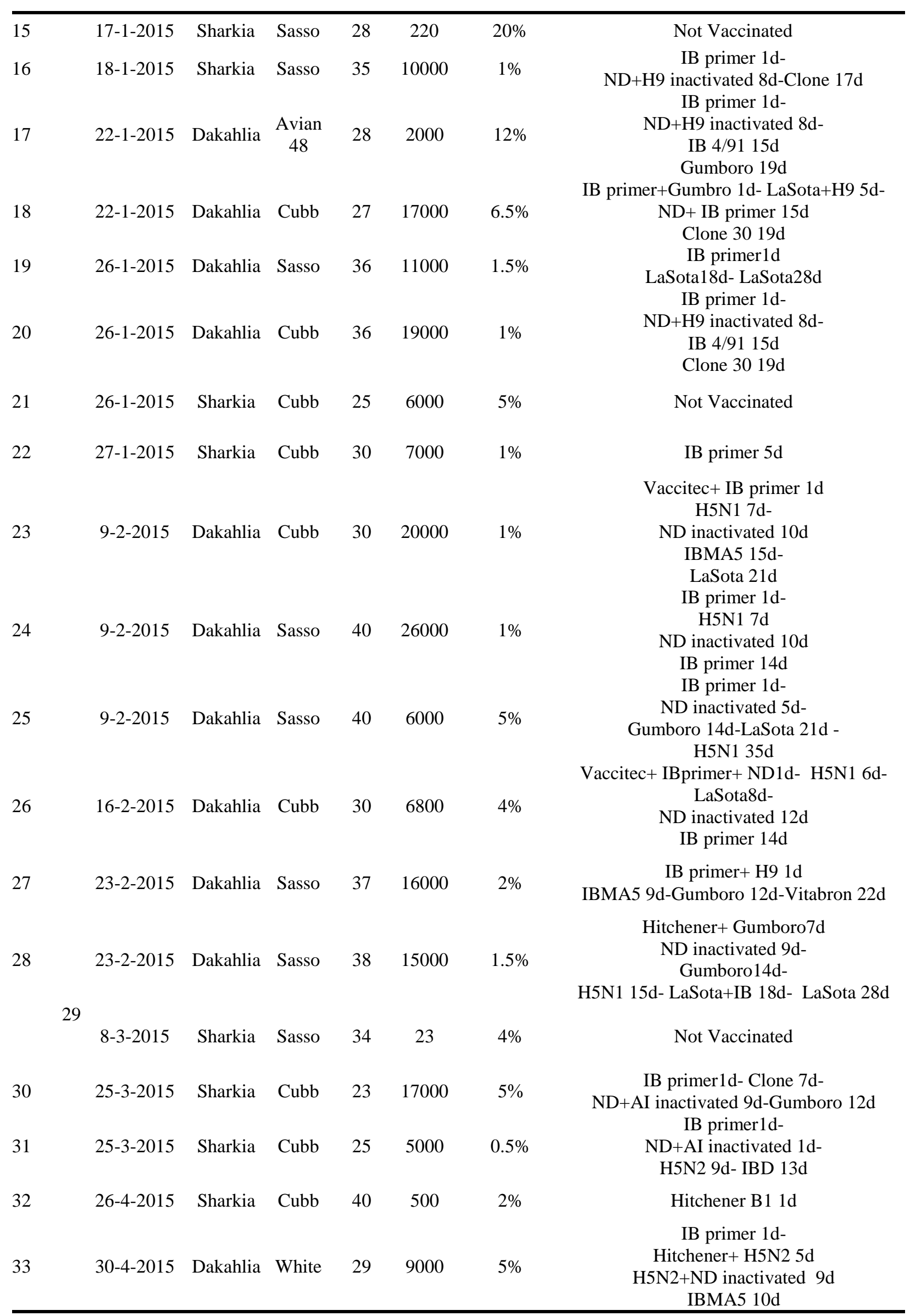




\begin{tabular}{|c|c|c|c|c|c|c|c|c|}
\hline & & & & & & & & LaSota19d \\
\hline 34 & & $30-4-2015$ & Sharkia & Sasso & 22 & 6000 & $8 \%$ & $\begin{array}{c}\text { IB primer1d } \\
\text { H5N1 5d } \\
\text { ND inactivated 9d }\end{array}$ \\
\hline \multirow[t]{2}{*}{35} & & $30-4-2015$ & Dakahlia & Sasso & 36 & 4800 & $4.3 \%$ & $\begin{array}{c}\text { Vaccitec+ IB primer+ Avenu 1d- H9+ND } \\
\text { inactivated } 5 \mathrm{~d}- \\
\text { H5+LaSota } 12 \mathrm{~d} \\
\text { IB primer } 18 \mathrm{~d}\end{array}$ \\
\hline & 36 & $30-4-2015$ & Dakahlia & Cubb & 19 & 5000 & $16 \%$ & $\begin{array}{l}\text { Hitchener } 6 \mathrm{~d}- \\
\text { Gumboro } 12 \mathrm{~d}\end{array}$ \\
\hline \multirow[t]{2}{*}{37} & & $12-5-2015$ & Sharkia & Balady & 40 & 45 & $2 \%$ & Not Vaccinated \\
\hline & 38 & $12-5-2015$ & Sharkia & Ross & 27 & 2500 & $6 \%$ & $\begin{array}{l}\text { Hitchener } 7 d- \\
\text { Gumboro } 14 d \\
\text { IB primer1d } \\
\text { Hitchener } 7 d\end{array}$ \\
\hline 39 & & $28-5-2015$ & Dakahlia & Balady & 45 & 8000 & $1.5 \%$ & $\begin{array}{c}\text { Gumboro 12d } \\
\text { Clone30 20d } \\
\text { LaSota 45d }\end{array}$ \\
\hline 40 & & $4-6-2015$ & Dakahlia & Cubb & 29 & 20000 & $8 \%$ & $\begin{array}{c}\text { Vaccitec 1d } \\
\text { H5N1+ LaSota 10d } \\
\text { LaSota 20d }\end{array}$ \\
\hline 41 & & $4-6-2015$ & Dakahlia & Cubb & 26 & 10000 & $1 \%$ & $\begin{array}{c}\text { Vaccitec+ ND +IB primer } 1 \mathrm{~d}- \\
\text { H5N1 7d- } \\
\text { LaSota 10d- } \\
\text { Clone + IB 17d }\end{array}$ \\
\hline 42 & & $14-6-2015$ & Sharkia & Avian48 & 26 & 11000 & $10 \%$ & $\begin{array}{l}\text { IB H120 1d- } \\
\text { ND+H9 inactivated } 7 \mathrm{~d} \\
\text { IBD } 13 \mathrm{~d}- \\
\text { Clone } 3018 \mathrm{~d}\end{array}$ \\
\hline 43 & & $14-6-2015$ & Sharkia & Cubb & 24 & 5000 & 3 & $\begin{array}{l}\text { Hitchener }+ \text { IB } 1 \mathrm{~d} \\
\text { ND inactivated } 5 \mathrm{~d} \\
\text { IBD } 12 \mathrm{~d} \\
\text { Clone } 3017 \mathrm{~d}\end{array}$ \\
\hline 44 & & $20-6-2015$ & Dakahlia & Cubb & 35 & 11500 & $10 \%$ & $\begin{array}{c}\text { IB primer 1d } \\
\text { H5N16d } \\
\text { LaSota 9d } \\
\text { ND inactivated 11d }\end{array}$ \\
\hline
\end{tabular}

Mortality rate was calculated till submission day.

\section{Sample preparation}

Tissue pools of respiratory organs (tracheas, bronchi, lungs) and kidneys (3/each) were taken separately from the examined flocks $(n=44)$. The tissue suspension was prepared and antibiotics (penstrept Biowhit taker) were added to supernatants [14].

\section{Virus isolation}

Tissue supernatants $(0.2 \mathrm{~mL} / \mathrm{each})$ were inoculated into five (9-11days) ECE via allantoic cavity route. The dead embryos were collected and left to be chilled at $4{ }^{\circ} \mathrm{C}$ for overnight then allantoic fluids were harvested aseptically and examined for HA activity. Embryos examined for any lesions indicate of IBV infection [15].

\section{Detection of IBV by RT-PCR}

\section{RNA Extraction}

Total RNA was extracted from suspected original tissues and allantoic fluids by Gene JET RNA Purification Kit (Thermo Scientific TM \# K0731).

cDNA synthesis

The cDNA synthesis was carried out in 20 $\mu \mathrm{L}$ Vol. using revert Aid first strand cDNA 
synthesis kit (Thermo Scientific ${ }^{\mathrm{TM}}$ \# K0731). The reactions were incubate at $37^{\circ} \mathrm{C}$ for 60 min then at $42^{\circ} \mathrm{C}$ for 60 min later on it was terminated by heating at $70^{\circ} \mathrm{C}$ for $5 \mathrm{~min}$. followed by cooling at $4^{\circ} \mathrm{C}$ for $15 \mathrm{~min}$.

\section{RT-PCR reaction}

The RT-PCR was performed in a total of 25 $\mu \mathrm{l}$ in a sterile $0.2 \mathrm{~mL}$ RNase free PCR tubes. For one reaction, the assay optimized to $12.5 \mu \mathrm{L}$ of Dream Taq Green PCR Master Mix (2X), $0.25 \mu$ Lof selected forward and reverse primers $(100 \mathrm{pmole} / \mu \mathrm{l}), 2 \mu \mathrm{L}$ of $\mathrm{cDNA}$ and $10 \mu \mathrm{L}$ of RNase- free water [16].

The optimized PCR cyclic reaction condition preformed in MWG-Biotech Thermal cycler and described as following: PCR cycle for detection of IBV using a pair of primers F: 5'- GCT TTT GAG CCT AGC GTT-3', R: 5'-GCC ATG TTG TCA CTG TCT ATT-3' [16]

Each cycle of PCR includes steps for template denaturation, primer annealing and primer extension. The initial step denatures the target DNA by heating it to $94^{\circ} \mathrm{C}$ for $3 \mathrm{~min}$. In the denaturation process, the two intertwined strands of DNA separate from one another, producing the necessary single-stranded DNA template for replication by the thermostable DNA polymerase. In the next step of a cycle, the temperature is reduced to approximately $52^{\circ} \mathrm{C}$. At this temperature, the oligonucleotide primers can form stable associations (anneal) with the denatured target DNA and serve as primers for the DNA polymerase. This step lasts approximately $30 \mathrm{~s}$. Finally, the synthesis of new DNA begins as the reaction temperature is raised to the optimum for the
DNA polymerase to approximately $72^{\circ} \mathrm{C}$. The extension step lasts approximately $30 \mathrm{~s}$.

\section{Agrose gel electrophoresis of RT-PCR}

Electrophoresis was done at 100 voltes for $40 \mathrm{~min}$ and the bands were viewed by UV trans-illuminator [16].

\section{Results}

\section{Clinical Findings}

Clinically examined chickens showed general signs of illness and respiratory troubles including (sneezing, coughing, rales, gasping and nasal discharges) in all flocks. Whitish diarrhea was observed in Eighteen flocks (40\%) while Greenish diarrhea was observed in thirteen flocks (29\%). Mortality rates ranged from $(0.5-30 \%)$; in investigated flock suffering from respiratory troubles (caseated plug) it ranged from (0.5-20\%); and increased to $30 \%$ when associated with renal affection. It ranged from $(0.5-30 \%)$ in positive HA flocks. In positive single IB cases the mortality rates ranged from (5-10\%) while in cases IB mixed with hemagglutinating agent was (1-16\%)

Necropsy revealed tracheitis, bronchitis and congestion of lungs in all flocks. Caseated plugs at tracheal bifurcation $(n=28)$ (Figure 1 A,B). Beside CRD lesions (fibrinous pericarditis, perihepatitis, air saccculitis) $(n=19)$. Kidney damage in the form of nephritis -nepherosis with urate deposition in the ureters $(n=22)$. Nephritis (Figure $1 \mathrm{C}$ ) as well as swollen and pale kidneys with prominent tubules was observed (Figure $1 \mathrm{D}$ ). General congestion and hemorrhages were noticed on Proventriculus, Cecal tonsils were enlarged and ulcerated. 


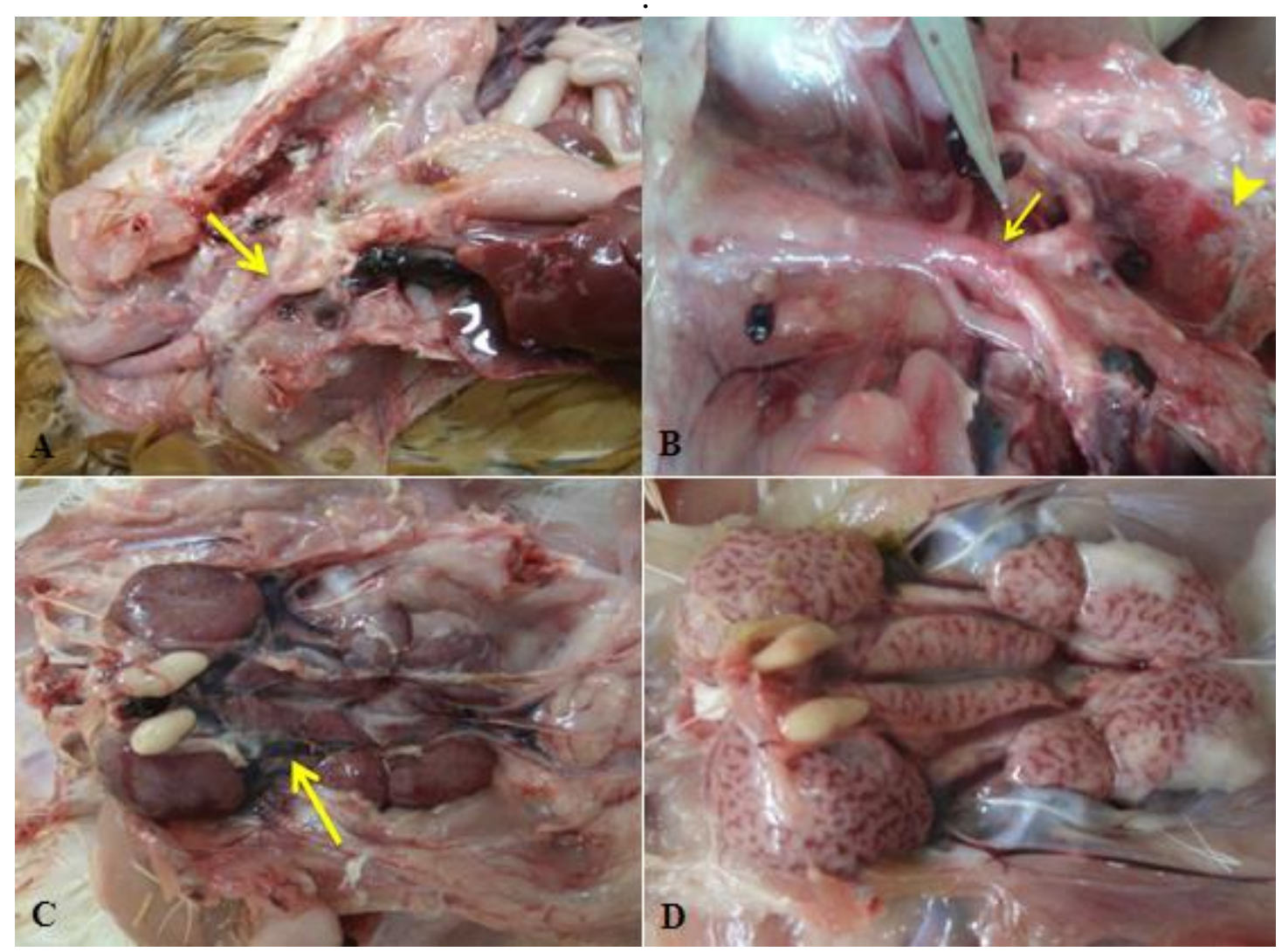

Figure 1: Postmortem lesions of examined flocks. A. Trachea of 29 day old broiler chicken (farm No.33) containing caseated plug in tracheal bifurcation. B. Trachea of 26 day old broiler chicken (farm No.42) containing caseated plug in tracheal bifurcation and Cloudiness of air sacs (arrow head). C. Kidney of 28 day old broiler chicken (farm No.17) showing Nephritis. D. Kidney of 29 day old broiler (farm No.40) showing severe Nephrosis (swollen and pale kidneys with prominent tubules).

\section{Isolation on ECE and HA results}

Embryo death with congestion within $1^{\text {st }} 72 \mathrm{hrs}(\mathrm{n}=24)$ were recorded and size of embryo was reduced during first passage $(n=9)$. While, five flocks required 3-6 blind passages to show reduction in embryo size up to $2 \mathrm{~cm}$ in comparison to its negative control 5 cm (Table 2).

Thirty three out of forty four harvested allantoic fluids showed agglutination of washed chicken RBCs $10 \%$ with percentage of $(75 \%)$ while eleven failed to agglutinate RBCs (Table 2). 
Table 2: IBV isolation and molecular identification from affected broiler chickens at Sharkia, Dakhalia and Gharbia Governorates during 2014-2015

\begin{tabular}{|c|c|c|c|c|c|}
\hline \multirow{2}{*}{$\frac{\text { Sample }}{\text { No. }}$} & \multirow[t]{2}{*}{ ECE Lesions } & \multirow{2}{*}{$\begin{array}{l}\text { HA } \\
\text { test }\end{array}$} & \multicolumn{3}{|c|}{ IBV Detection } \\
\hline & & & $\begin{array}{l}\text { RT-PCR } \\
\text { (Trachea) }\end{array}$ & $\begin{array}{l}\text { RT-PCR } \\
\text { (Kidney) }\end{array}$ & $\begin{array}{c}\text { RT-PCR } \\
\text { Allantoic fluid }\end{array}$ \\
\hline 1 & Small & - & - & - & - \\
\hline 2 & Congested* & + & - & - & - \\
\hline 3 & congested & + & - & - & - \\
\hline 4 & congested & + & - & - & - \\
\hline 5 & congested & + & - & - & - \\
\hline 6 & small & - & - & - & - \\
\hline 7 & congested & + & - & - & - \\
\hline 8 & congested & + & - & - & - \\
\hline 9 & congested & + & - & - & - \\
\hline 10 & small & - & - & - & - \\
\hline 11 & congested & + & - & - & - \\
\hline 12 & small & - & - & + & + \\
\hline 13 & small & - & - & - & - \\
\hline 14 & congested & + & - & - & - \\
\hline 15 & congested & - & - & - & - \\
\hline 16 & small & - & - & - & - \\
\hline 17 & congested & + & - & + & - \\
\hline 18 & congested & + & - & + & - \\
\hline 19 & congested & + & - & - & - \\
\hline 20 & congested & + & - & - & - \\
\hline 21 & congested & + & - & - & - \\
\hline 22 & congested & + & - & - & - \\
\hline 23 & congested & + & - & + & - \\
\hline 24 & congested & + & - & - & - \\
\hline 25 & congested & + & - & - & - \\
\hline 26 & congested & + & - & - & - \\
\hline 27 & congested & + & - & - & - \\
\hline 28 & congested & + & - & - & - \\
\hline 29 & congested & + & - & - & - \\
\hline 30 & congested & + & - & - & - \\
\hline 31 & congested & + & - & - & - \\
\hline 32 & congested & + & - & - & - \\
\hline 33 & small & - & + & + & - \\
\hline 34 & congested & + & - & - & - \\
\hline 35 & small & - & - & - & - \\
\hline 36 & congested & + & + & + & - \\
\hline 37 & congested & + & - & - & - \\
\hline 38 & congested & + & - & - & - \\
\hline 39 & congested & + & - & - & - \\
\hline 40 & small & - & - & + & - \\
\hline 41 & congested & + & - & - & - \\
\hline 42 & congested & + & + & + & + \\
\hline 43 & congested & + & - & - & - \\
\hline 44 & small & - & - & + & - \\
\hline Total $\%$ & $20 \% * *$ & $75 \%$ & & & $4.5 \%$ \\
\hline
\end{tabular}

*Congested embryos were small due to earlier death

** Percentage of ECE showing small and dwarfed embryos. 


\section{Molecular identification using RT-PCR}

All samples suspected to be infected with IBV were identified by RT-PCR using specific primers. The results revealed 9 out of $44(20 \%)$ tissue samples were IBV Positive. However, Allantoic fluids of the same flocks only 2 flocks were IBV positive (Table 2 and Figure 2).

The analysis of the relatedness of clinical findings, virus isolation and Rt-PCR results was illustrated in Figure (3).

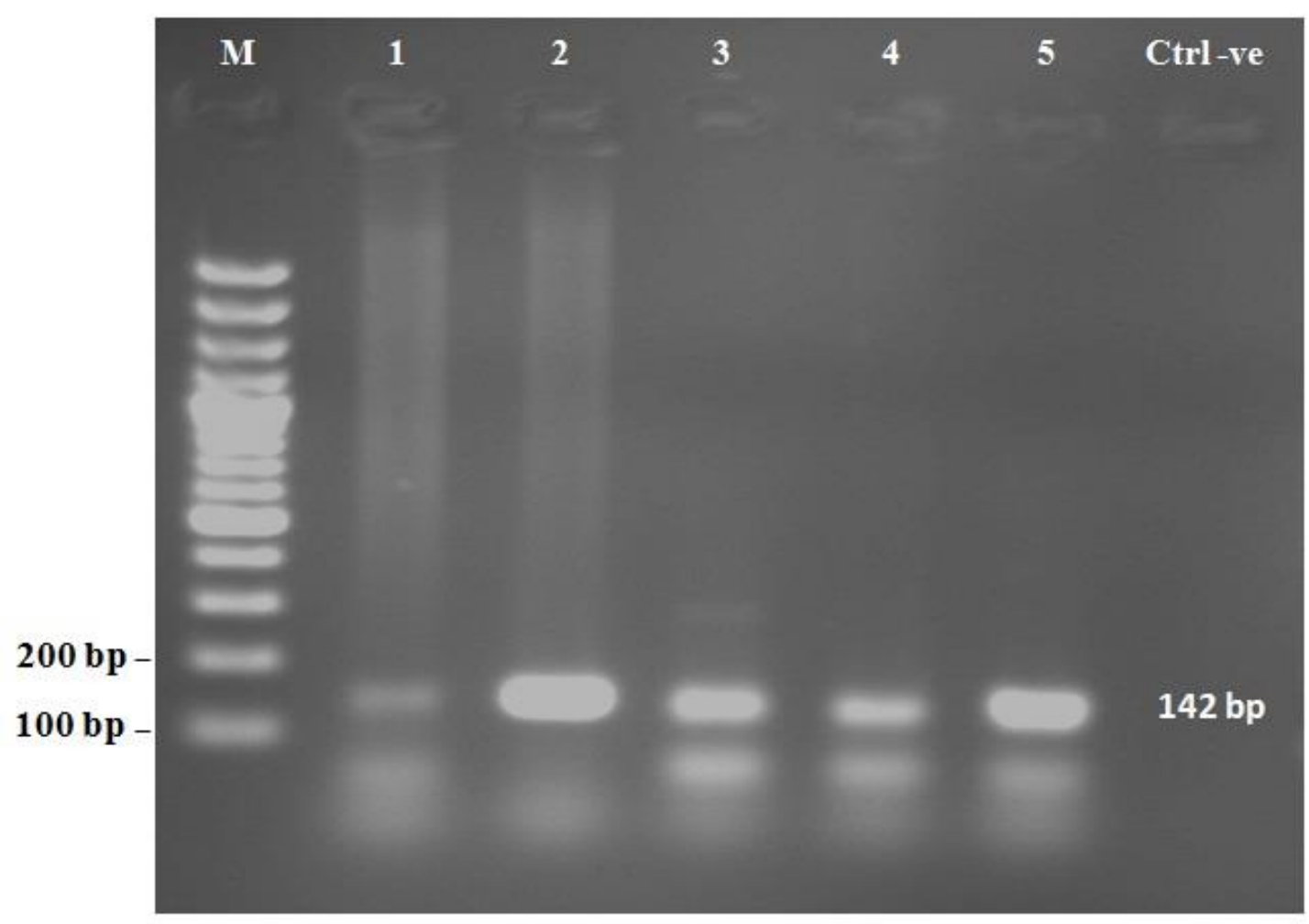

Figure 2: Molecular identification of IBV using RT-PCR: Agarose gel electrophoresis of the RT-PCR products of IBV. Lane(M): DNA ladder (marker) 100pb. Lane (1) positive IBV represents the tested sample No 12(kidney). Lane (2) positive IBV represents the tested sample No 40 (kidney). Lane (3) positive IBV represents the tested sample No 42(trachea). Lane (4) positive IBV represents the tested sample No 42(kidney). Lane (5) positive IBV represents the tested sample No. 33 (trachea). All positive samples showed band at 142 bp Lane (ctrl -ve): negative control. 


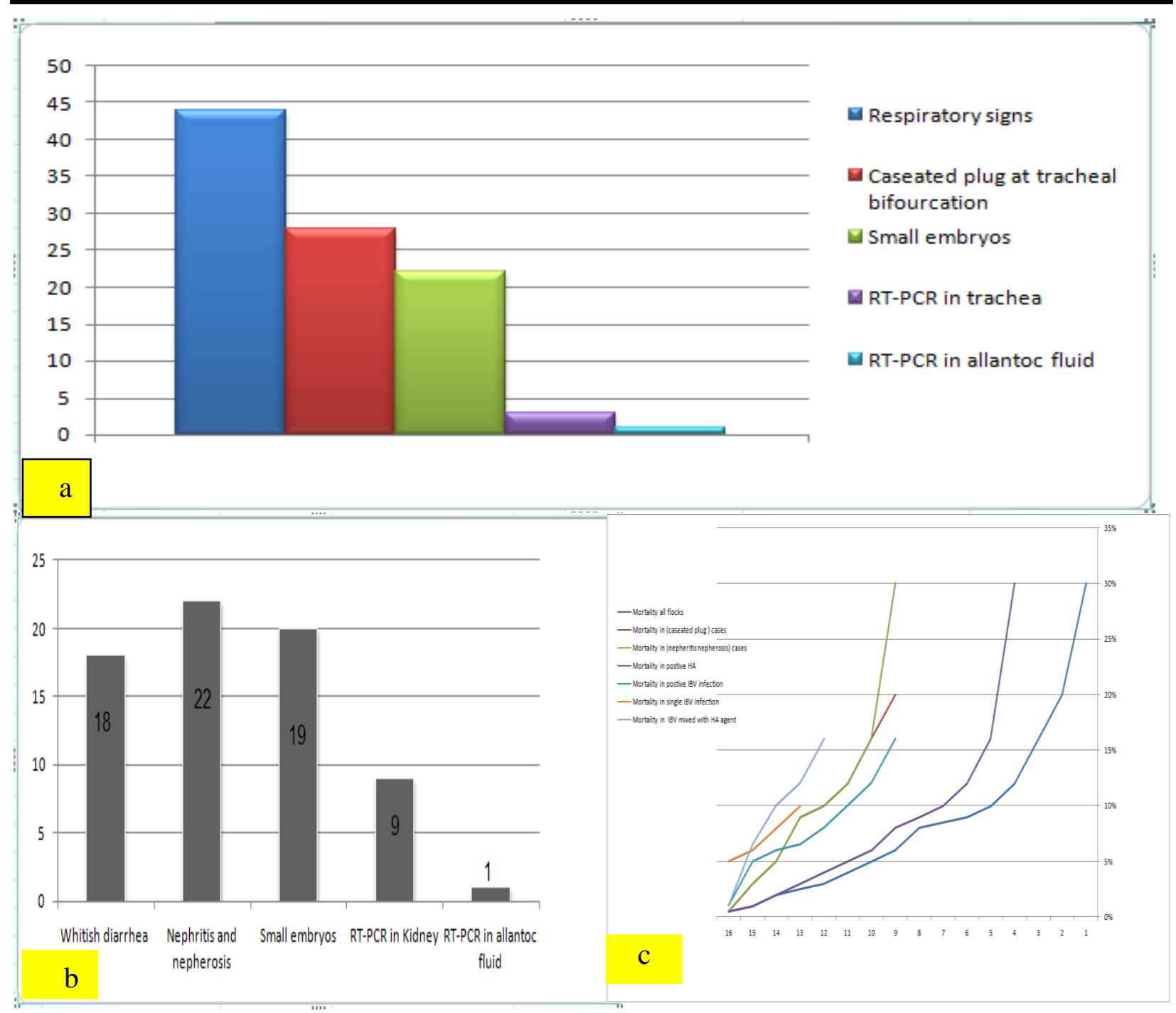

Figure 3: Relatedness between clinical and laboratory diagnosis of IB; a. Respiratory cases, b. Renal cases and c. mortality pattern

\section{Discussion}

Infectious bronchitis (IB) has occurred frequently in vaccinated as well as non vaccinated chicken farms causing harsh economic losses so this study aimed to throw light on the responsibilities of IBV on respiratory and renal troubles in broiler chickens in Sharkia, Dakalia and Gharbia Governorates. The obtained results revealed that the frequently observed clinical signs among examined broiler flocks were depression, huddling together under a heat source with profound reduction in feed consumption. The respiratory signs were the main, and ranged from mild to marked gasping, sneezing, coughing, nasal discharges, with sinus swelling. Other examined birds showed renal signs in the form of whitish diarrhea in $41 \%$ of the examined flocks. The obtained results were analogous to that previously recorded in IBV infection [17-20].

Mortality rates varied from 0.5 to $30 \%$. There was a positive relation between the severity of clinical picture, and number of detected agents. Also the association of renal signs exacerbated the mortality (30\%) among affected flocks. These findings are not dissimilar to the previously reported by Chone and Apostolov [21] Bastami et al.[22] and Ziegler et al.[23] In Egypt, Commercial 
poultry flocks have highly regarded mortalities associated mainly with respiratory and renal troubles [13,24,25]

The postmortem lesions included tracheitis, bronchitis and congestion of lungs in all flocks followed by caseated plugs at tracheal bifurcation occurred in 28 flocks. Kidney damage in the form of nepherosis-nephritis with urate deposition in the ureters was seen in 22 flocks. Additionally some birds exhibited hemorrhages in proventriculus and general congestion, Also fibrinous pericarditis, perihepatitis, air sacculitis Similarly, variable lesions were recorded in former IBV single and mixed infections in chickens [23,26-28]. The presence of fibrinous inflammation indicated complication with bacterial infection. The finding was in agreement with that of Awad et al. [29] who recorded that IBV infection is commonly followed by secondary bacterial infection however the hemorrhagic lesions in visceral organs may be pointing to concurrent severe viral agents. Therefore in flocks under field conditions it is thought that infection with these isolates would also predispose chicks to bacterial and or viral infections, resulting in complicated morbidity and increased mortality [28-30]

Embryo death within 72 hrs PI was recorded in $54.5 \%$ of inoculated samples. The allontoic fluids of these embryos revealed positive HA activity that suggesting virulent hemagglutinating viral infection which may be of ND and /or AI viruses in the same way Eid [31] recorded the rapid embryo death with positive HA activity in both ND and AI virus infections in Egyptian chicken flocks.

Reduced Embryo size was evidenced during first embryo inoculation $20 \%$ and $11 \%$ required 3-6 blind passages to show reduction in chicken embryo size up to $2 \mathrm{~cm}$ in comparison to its negative control $5 \mathrm{~cm}$. The recorded results were considered evocative to IBV infection as recorded by Jordan and Nassar [32]

Using specific primers, 9 flocks were IBV Positive to IBV including 6 from renal the examined tissues but only 3 were detected in both renal and respiratory tissues. The examination of their allantoic fluids with the same primers revealed dramatic decrease in
IBV detection to be in only 2 flocks $(12,42)$ with a percentage of $4.5 \%$. Correspondingly the IBV was evidenced positive using the same primer band at $142 \mathrm{bp}$ By Callison et al.[16] and Awad et al. [29] who stated that the Taqman RT-PCR assay using a specific primer succeeded in detection of infectious bronchitis virus from infected chickens.

The hemagglutinating agents were detected in $75 \%$ of the examined flocks comparable results were recently recorded by Hassan [28] who reported the occurrence of HA viruses in $86 \%$ of the investigated flocks with respiratory and or renal affections in north Shrakia during 2012-2013.

Mixed virus infections were recorded in 5 out of $9(55.6 \%)$ of IBV positive samples. likewise many authors stated that IBV was frequently isolated with other viral and /or bacterial infection $[30,33]$

In a trial to analyze the role of different vaccine protocols applied among investigated flocks to protect birds from IB virus infection, the obtained information were as follows 1 : The IBV was isolated from both classic and variant virus vaccinated flocks; 2: Neither once nor twice vaccination prevent IBV infections e.g. the virus was isolated in birds vaccinated only with classic virus at day 1 of age as in flock 42 and in flocks received both classic (Ma5) and variant ( primer vaccine ) or $4 / 91$ vaccines as in 12,17,18, 23, 33, 36 and 44 flocks. On the same level non vaccinated flocks (36 and 40) revealed positive IBV detection. Correspondingly, many authors explained their findings by little or no cross protection of vaccinal strains against field circulating ones [24,34].Vaccine failure may be attributed also to misapplication of vaccine or impaired immune status of the birds and concurrent infections as previously mentioned $[12,35]$

The correspondence of field observations and laboratory IBV isolation and identification was analyzed. It was found that 44 chicken flocks suffering from respiratory signs and have caseated plugs in tracheal bifurcation among 28 ones. Only three IB virus isolates were identified in their tissues which were reduced to one after embryo passage. Similar pattern was observed among renal affections in 
22 flocks and virus isolation was evidenced in 9 while only one allantoic fluid sample positive for IBV. The obtained findings could be explained by; 1: the high incidence of concurrent HA viruses detected in allantoic fluids of 33 samples; 2: presence of latent virus infection and /or maternal derived antibodies (MDA) in chicken embryos which may interfere with IBV replication $[28,36]$

It is clear that, despite the different vaccine program against IB and hemagglutinating (ND and $\mathrm{AI}$ ) viruses, concurrent virus infections were commonly recorded among chickens and still causing bad economic impact on this industry. The HA virus spread interfered with the routine protocol of IBV diagnosis.

\section{Conclusion}

It could be concluded that; The IB virus infection did not exceed $20 \%$ of the causative agents in disease condition in question and usually in mixed infection. In, turn the use of variant vaccines did not solve the problem but exacerbated the emergence of new IB viruses, There were clear evidence that HA virus did the main role in such disease problems and the applied vaccine programs against ND and AI viruses succeeded only to minimize rather than to prevent them.

\section{Conflict of interest}

The authors have no conflict of interest to declare.

\section{References}

[1] El-Bakrey, R. M. (2014): Molecular and Immunological Studies on Genetic Variation of AI viruses Isolated in Egypt. Ph.D. Thesis, Avian and Rabbit Medicine Department. Faculty of Veterinary Medicine. Zagazig University. Egypt

[2] El-Sisi, M.A. and Eid, A.A.M. (2000): Infectious bronchitis virus and infectious bursal disease; concurrent infection among broilers in Egypt. Zagazig Veterinary Journal, 28: 150-153.

[3] Lebdah, M.A.; Eid, A.A.M. and El-Shafey, A.M. (2004): infectious bronchitis virus infection among meat type chickens in Sharkia Province (Egypt). Proceeding of the IV. International symposium on avian corona and pneumovirus infections Rauischholzhausen, Germany, 20-23.

[4] Cavanagh, D. and Naqi, S. (2003): Infectious bronchitis in: Diseases of Poultry; 11th ed. By: Saif YM, Barnes HJ, Glisson JR, Fadly AM, McDougald LR, Swayne DE. Ames: Iowa State University Press, 101-119.

[5] Saif,Y.M.; Swayne,D.E.; Glisson, J.R.; McDougald, L.R.; Nolan, L.K.; Suarez, D.L. and Nair, V., (2013): Diseases of poultry, 13 Edition Chapter 4, Infectious Bronchitis: 139-159

[6] Mayo, M.A. and Pringle, C.R. (1998): Virus Taxonomy 1997. Journal of General Virology,, 79:649-657.

[7] Cook, J.K.A. (1984): The classification of new serotypes of infectious bronchitis virus isolated from poultry flocks in Britain between 1981 and 1983. Avian Pathology, 13: 733-741.

[8] Wang, H.N.; Wu, Q.Z.; Huang, Y. and Liu, P. (1997): Isolation and identification of Infectious Bronchitis virus from chickens in Sichuan. China. Avian Diseases, 41: 279-282.

[9] Ma, F.L.; Fu, X.L.; Chen, G.Z.; Jia, S.Y.; Chen, R.M.; Liu W.S. and Xuan H. (2004): The isolation, identification and experimental vaccination of avian Infectious Bronchitis virus causing proventriclitis. Chinese Journal of Science, 24, 225-227.

[10] Song, C.S.; Lee, Y.J.; Kim, J.H.; Sung, H.W.; Lee, C.W. and Izumiya, Y. (1997): Epidemiological classification of infectious bronchitis virus isolated in Korea between 1986 and 1997. Avian Pathology, 27:409-16.

[11] Bayry, J.; Goudar, M.S.; Nighot, P.K.; Kshirsagar, S.G.; Ladman, B.S. and Gelb, Jr. J. (2005): Emergence of nephropathogenic avian infectious bronchitis virus with a novel genotype in India. Journal of Clinical Microbiology, 43(2):916-8.

[12] Cavanagh, D. (2007): Coronavirus avian infectious bronchitis virus. Veterinary Research, 38: 281-297. 
[13] Zanaty, A.M.M. (2014): Epidemiological and molecular studies on the current status of infectious bronchitis disease in Egypt. Ph.D. Thesis; Department of poultry disease; Beni-Seuf University. Egypt.

[14] Numan, M.; Siddique, M.; Shahid, M.A. and Yousaf, M.S. (2008): Characterization of isolated avian influenza virus. Journal of Veterinary and Animal Sciences, 1: 24-30.

[15] Jackwood, M.W. and Gelb, J.J. (1998): A laboratory manual for the isolation and identification of avian pathogens. 4th Ed. Ch.32; Infectious Bronchitis:169-174.

[16] Callison, S.A.; Hilt,D.A.; Boynton, T.O.; Sample B.F.; Robison, R.; Swayne, D. and . Jackwood, M.W. (2006): Development and evaluation of a realtime Taqman RT-PCR assay for the detection of infectious bronchitis virus from infected chickens. Journal of Virological Methods, 138:60-65.

[17] Winterfield, R.W. and Albassam, M.A. (1984): Nephropathogenicity of IBV. Poultry Science, 63: 2358-2363.

[18] El-Houadfi M.D.; Jones R. C.; Cook J.K.A. and Ambali A.G. (1986): The isolation and characterization of avian IBV isolated in Morocco. Avian Pathology, 15:93-105.

[19] Bastami, M.A.; Amer, M.M. and Hamouda, A.S. (1987): A viral nephritis induced by an isolate related to infectious bronchitis virus: I- Isolation and identification of isolate. Assiut Veterinary Medical Journal; 19 (37): 171-178.

[20] El-Shafey, A.M. (2008): Advanced study on infectious bronchitis of chicken in Egypt. Master Thesis of Poultry diseases; Zagazig University,; Egypt.

[21] Chone, K.T. and Apostolove, K. (1982): The pathogenesis of nephritis in chickens induced by IBV, Journal of Comparative Pathology, 92 (2): 199-211.

[22] Bastami, M.A.; El-kady, M.F. and Mostfa, M. (1991): Viral nephritis induced by an isolate related to infectious bronchitis virus: II- Pathogenicity of the isolated viral nephritis strain of chickens of different ages. Beni-Seuf Veterinary Medicine and Research, (1): 195-203.

[23] Ziegler, A.F.; Ladman, B.S.; Dunn, P.A.; Schneider, A.; Davison, S.; Miller, P.G.; Weinstock, D.; Salem, M.; Eckroade, R.J. and Gelb, J.J. (2002): Nephropathogenic infectious bronchitis in Pennsylvania chickens 1997-2000. Avian Diseases, 46(4): 847-58.

[24] Mourad, A.A.H. (2012): Recent Status of Infectious Bronchitis Disease in Broiler Flocks in Egypt. M.V.Sc. Thesis of Poultry Diseases; Faculty of Veterinary Medicine Zagazig University, Egypt.

[25] Abo-Elkhair, M.; Bazid, A.I.; Abd ElRazak, A.G.; Zidan, S.A. and Sultan, H. (2014): The Role of Avian Influenza Virus (Subtypes H9 and H5) and Avian Infectious Bronchitis Virus in an Outbreak Affecting Commercial Poultry Flocks in Egypt During 2012. Benha Veterinary Medical Journal, 27(2): 21-28.

[26] King, D.J. and Cavanagh, D. (1991): Infectious Bronchitis in B.W.M. Reid and H, V. Yoder, Jr (eds) Diseases of Poultry, Ames, Iowa, Iowa state University press

[27] Kang-Seuk, C.; Lee, E.K.; Woo-Jin, J.; Mi-Ja, P.; Jin-Won, K. and Kwon, J.H. (2009): Pathogenicity and antigenicity of a new variant of Korean nepheropathogenic infectious bronchitis virus. Journal of Veterinary Science, 10(4)357-359.

[28] Hassan, T.R. (2015): Viral Agents Associated with Complicated Chronic Respiratory Disease in Briolers. master Thesis, Avian and Rabbit Medicine Department; Faculty of Veterinary Medicin; Zagazig University; Egypt.

[29] Awad, F.; Chhabra, R.; Baylis, M. and Ganapathy, K. (2014): An overview of Infectious Bronchitis virus in chickens World's Poultry Science Journal,70.

[30] Gado, H.A. (2014): Studies on occurrence of AI H9 virus in chickens, master Thesis, Avian and Rabbit Medicine Department; Faculty of Veterinary Medicin; Zagazig University; Egypt. 
[31] Eid, A.A.M. (1998): Infectious bronchitis in Egypt. Proceeding of the international Symposium on Infectious Bronchitis and Pneumovirus infections in poultry. Rauischholzausen; Germany; 15-18 June 1998; pp.145-156.

[32] Jordan, F.T.W. and Nassar T.J. (1973): The survival of infectious bronchitis virus in water. Avian Pathology 2 (2): 91-101.

[33] Ahmed, Z.M., Hussein, H.A. and Rohaim, M.A. (2013): Efficacy of Composting Poultry Mortality and Farms Wastes with Mixed Respiratory Infection Viruses H9N2 and NDV in Egypt. Global Veterinaria, 11(2): 177-185.
[34] El-Mahdy S. S.; Soliman, Y.A. and ElHady, M.M. (2011): preparation and evaluation of master seed for infectious bronchitis vaccine from local variant isolate. Nature and Science, 9 (10):145151.

[35] Davelaar, F.G.; Kouwenhoven, B. and Pejkovski, C. (1979): Immunosupperssive effect of infectious bursal disease virus on vaccination against Infectious Bronchitis. Avian Pathology, 8:95-106.

[36] Beard, C.W. (1967): Infectious bronchitis virus interference with Newcastle disease virus in monolayers of chicken kidney cells. Avian Diseases, 11:399-406

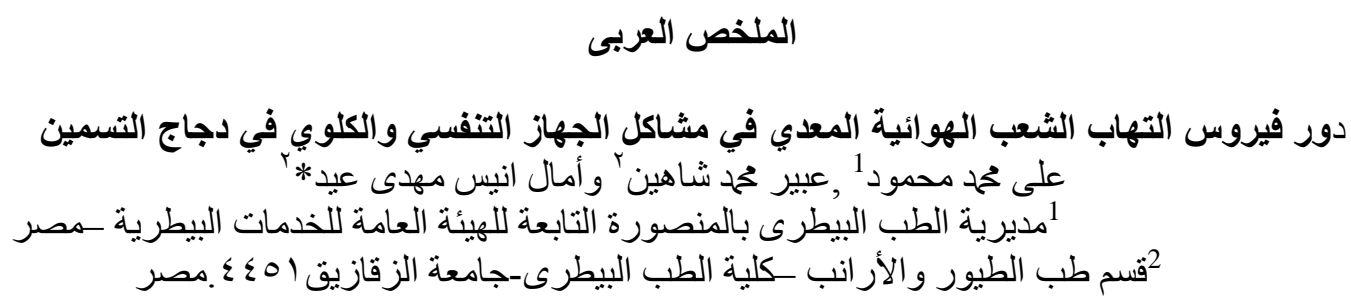

يمثل دجاج التسمين في مصر المصدر الرئيسي للبروتين الحيواني و لسوء الحظ ، عادة ما يصاب بالعديد من المشاكل

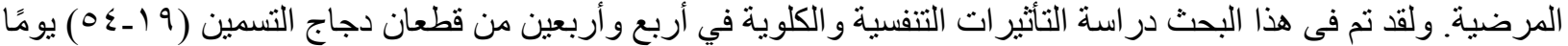

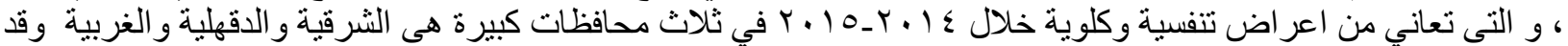

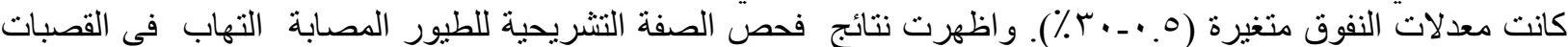

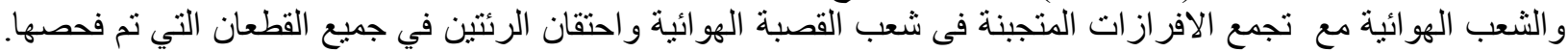

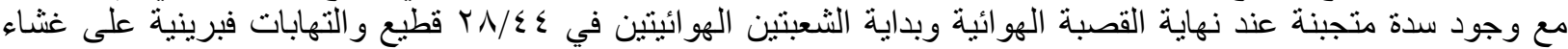

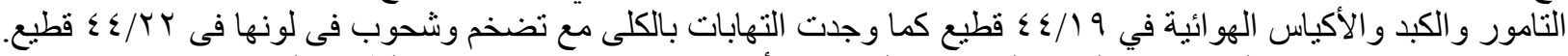

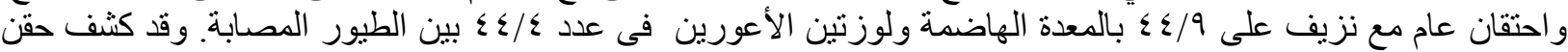

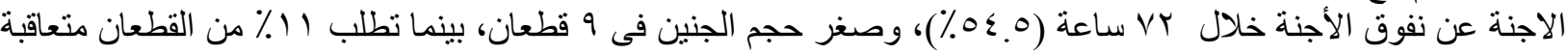

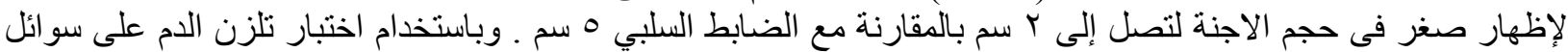

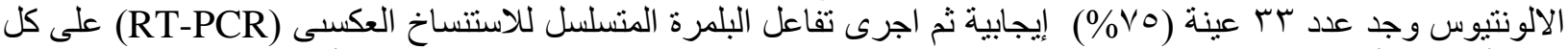

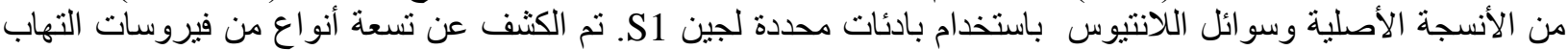

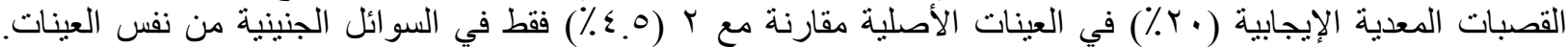

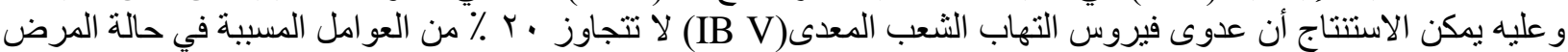

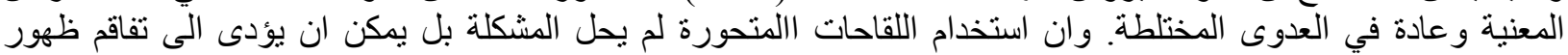

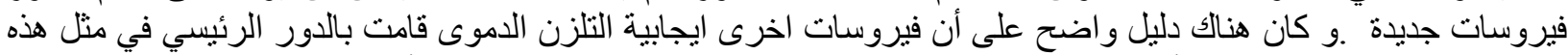

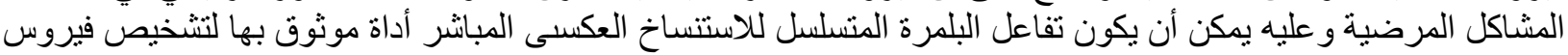

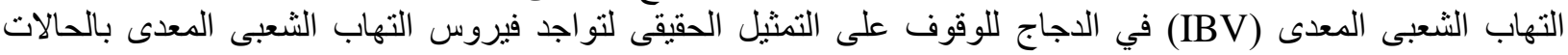
المرضية بالدجاج. 